\title{
Plasma microbiome in COVID-19 subjects: an indicator of gut barrier defects and dysbiosis
}

Ram Prasad ${ }^{1}$, Michael John Patton², Jason L Floyd ${ }^{1}$, Cristiano Pedrozo Vieira ${ }^{1}$, Seth Fortmann ${ }^{1}$, Mariana DuPont ${ }^{1}$, Angie Harbour ${ }^{1}$, Chen See Jeremy ${ }^{3}$, Justin Wright ${ }^{3}$, Regina Lamendella ${ }^{3}$, Bruce R. Stevens ${ }^{4}$, and Maria B. Grant ${ }^{1 *}$

\section{AFFILIATIONS:}

${ }^{1}$ Department of Ophthalmology and Visual Sciences, ${ }^{2}$ Department of Medicine, University of Alabama at Birmingham, Birmingham, AL.

3Wright Labs, LLC, Huntingdon, PA.

${ }^{4}$ Department of Physiology and Functional Genomics, University of Florida, Gainesville, FL.

Short title: Plasma Microbiome in COVID -19 subjects

\section{*CORRESPONDENCE:}

Maria B. Grant, MD

Department of Ophthalmology and Visual Sciences

The University of Alabama at Birmingham,

1670 University BLVD, VH490 - Birmingham, AL 35294

Phone: 205.996.8685 office; Fax: 205.934.3425; E-mail: mariagrant@uabmc.edu

\section{Word Count: 3646}




\section{Abstract:}

The gut is a well-established route of infection and target for viral damage by SARS-

CoV-2. This is supported by the clinical observation that about half of COVID-19 patients exhibit gastrointestinal (GI) symptoms. We asked whether the analysis of plasma could provide insight into gut barrier dysfunction in patients with COVID-19 infection. Plasma samples of COVID-19 patients $(n=30)$ and healthy control $(n=16)$ were collected during hospitalization. Plasma microbiome was analyzed using $16 \mathrm{~S}$ rRNA sequencing, metatranscriptomic analysis, and gut permeability markers including FABP-2, PGN and LPS in both patient cohorts. Almost 65\% (9 out 14) COVID-19 patients showed abnormal presence of gut microbes in their bloodstream. Plasma samples contained predominately Proteobacteria, Firmicutes, and Actinobacteria. The abundance of gram-negative bacteria (Acinetobacter, Nitrospirillum, Cupriavidus,

Pseudomonas, Aquabacterium, Burkholderia, Caballeronia, Parabhurkholderia, Bravibacterium, and Sphingomonas) was higher than the gram-positive bacteria (Staphylococcus and Lactobacillus) in COVID-19 subjects. The levels of plasma gut permeability markers FABP2 (1282 \pm 199.6 vs 838.1 $\pm 91.33 ; \mathrm{p}=0.0757), \mathrm{PGN}(34.64 \pm 3.178$ vs $17.53 \pm 2.12 ; \mathrm{p}<0.0001)$, and LPS (405.5 \pm 48.37 vs 249.6 $\pm 17.06 ; \mathrm{p}=0.0049)$ were higher in COVID-19 patients compared to healthy subjects. These findings support that the intestine may represent a source for bacteremia and may contribute to worsening COVID-19 outcomes. Therapies targeting the gut and prevention of gut barrier defects may represent a strategy to improve outcomes in COVID19 patients.

Keywords: Circulating microbiome, COVID-19, gut barrier permeability, dysbiosis 


\section{Introduction:}

More than 2.8 million deaths related to COVID-19 have been reported worldwide, while this number is still increasing even after more than 18 months since the diagnosis of the first COVID-19 case. According to a report published by the CDC, between the March 2020-April 2021 in the United States, the overall number of COVID -19 case are higher in female subjects $(52.2 \%)$ than male $(47.8 \%)$, while the mortality rate is higher among males $(54.3 \%)^{1}$. The clinical manifestation of COVID-19 is more severe in patients with pre-existing and ongoing medical conditions including cardiovascular diseases, cancer, and diabetes ${ }^{2-9}$. Apart from respiratory symptoms, a large number of COVID-19 patients experience gastrointestinal (GI) symptoms including nausea, fever, pain, and diarrhea. Most common GI complication is severe diarrhea ${ }^{10}$. During hospitalization, critically ill patients experience GI complications ${ }^{11}$. In a USA-based study, approximately $61.3 \%$ of COVID-19 patients reported GI complications, including but not limited to loss of appetite (34.8\%), diarrhea (33.7\%), mesenteric arterial or venous thromboembolism, and small bowel ischemia ${ }^{12}{ }^{13}$. These Gl complications were associated with longer hospitalizations $^{14}$. In a meta-analysis of 107 studies and 15,133 patients combined, the pooled prevalence of GI complications was $10-33.4 \%{ }^{15-17}$. Although these studies confirm Gl findings and important clinical observations, they do not interrogate the pathophysiology associated with these GI complications. We asked whether COVID-19 patients demonstrated gut barrier defects and presence of a microbiome in their plasma. Our patient population were individuals admitted to the University of Alabama at Birmingham hospital (Birmingham, AL, USA) with a confirmed diagnosis of COVID-19 and nonCOVID-19 controls.

\section{Methods:}

\section{Study subjects:}

A total of 30 COVID-19 patients (P1-P30; Table 1$)$ and 16 healthy subjects $(\mathrm{H} 1-\mathrm{H} 16$; Table 2) were involved in this study. During hospitalization of the COVID-19 patients at UAB 
hospital, blood samples were collected under sterile conditions following Institutional Review Board guidelines. Blood samples from non-COVID-19 controls were collected following routine guidelines ${ }^{18}$. The COVID-19 patients were classified as mild (clinical symptoms with no sign of pneumonia), moderate (fever and respiratory symptoms), severe (any of the above criteria and following respiratory distress: $\geq 30$ breaths/min; oxygen saturation: $\leq 93 \%$ at rest; arterial partial pressure of oxygen/fraction of inspired oxygen: $\leq 300 \mathrm{mmHg}$; cases with chest imaging that shows lesion progression within $24-48 \mathrm{~h}>50 \%$ ), or critical (any of the above criteria and following respiratory failure, mechanical ventilation, shock, organ failure, and requires ICU care $)^{19}$.

\section{Limitations of the study:}

Due to the small volume $(200-300 \mu \mathrm{L})$ of plasma sample's availability, two different subsets of COVID-19 patients (P1-P14) for circulating microbiome and (P15-P30) for gut permeability marker analysis were used in the study.

\section{Microbial DNA extraction and 16S rRNA sequencing:}

The frozen plasma samples were shipped to Wright Labs, LLC. for the $16 \mathrm{~S}$ rRNA sequencing (V3-V4 region) and metatranscriptomic analysis. The microbial DNA was extracted from samples using the DNA/RNA Miniprep Kit (Zymo Research, Irvine, CA) according to the manufacturer's protocol. After extraction, DNA purity and concentration were determined using Qubit 4 Fluorometer (Invitrogen, Carlsbad, CA) and dsDNA HS assay kit (ThermoFisher Scientific, Waltham, MA). PCR products were pooled, and gel purified on a $2 \%$ agarose gel using Qiagen Gel Purification Kit (Qiagen, Frederick, MD). After quality check using 2100 Bioanalyzer and DNA 1000 chip (Agilent Technologies, Santa Clara, CA), 16S rRNA sequencing was performed using an Illumina MiSeq v2 chemistry with paired-end 250 base pair 
reads as per the Earth Microbiome Project's protocol ${ }^{20}$. One negative control was processed in parallel with the samples and sequenced as well.

\section{Bioinformatic analysis:}

Raw sequence data was successfully obtained and imported into Qiime2 for processing and analyses ${ }^{21}$. Initial quality in the form of Phred q scores was determined using Qiime2, while cumulative expected error for each position was determined with VSEARCH ${ }^{22}$. Based on these quality data, forward and reverse reads were truncated at a length of 250 , with a maximum expected error of 0.5 within Qiime2's implementation of the DADA2 pipeline ${ }^{23}$. Qiime2's DADA2 pipeline was also used to merge forward and reverse reads and removed chimeras and assign the remaining sequences to amplicon sequence variants (ASVs). Representative sequences were used to determine taxonomic information. The full report and statistical analysis from Wright Labs, Huntingdon, Pennsylvania is available upon request.

\section{Alpha and beta diversity analysis}

Alpha diversity was calculated by subsampling the ASV table at 10 different depths, ranging from 230 to 2300 sequences, for the Faith's Phylogenetic Diversity ${ }^{24}$, Observed OTUs ${ }^{25}$, Pielou's Evenness ${ }^{26}$, and Shannon's Index ${ }^{27}$ metrics. 20 iterations were performed at each depth to obtain average alpha diversity values for the different metrics. A rarefaction plot was created with the results of this subsampling to confirm that diversity approached an asymptote and slope decreased as depth increased. Averages for the greatest depth were calculated and plotted to show each sample's diversity.

Beta diversity analyses were conducted after the ASV table had first undergone cumulative sum scaling normalization ${ }^{28}$ to mitigate differences between samples based on sequencing depth. Distances between samples were calculated using the Weighted Unifrac 
metric $^{29}$ based on the normalized table and rooted tree. The resulting distance matrix was visualized as a Principal Coordinates Analysis plot in R.

\section{Measurement of gut permeability marker FABP2:}

The level of fatty acid-binding protein-2 (FABP2) $)^{30}$, a marker of intestinal barrier damage, was determined by ELISA in the plasma samples using a colorimetric assay kit (\#DFBP20, R\&D systems, Minneapolis, MN) following the manufacturer's protocol. The absorbance was measured at $450 \mathrm{~nm}$ using a microplate reader, and the levels of FABP2 were calculated as per the standard curve and expressed as $\mathrm{pg} / \mathrm{mL}$.

\section{Enzyme-linked immunosorbent assay for measuring gut microbial peptide translocation into the systemic circulation:}

The level of peptidoglycan (PGN) in plasma samples was measured using a colorimetric assay kit for mouse peptidoglycan (\#MBS263268, MyBioSource Inc., San Diego, CA) following the manufacturer's protocol. The absorbance was measured at $450 \mathrm{~nm}$ using a microplate reader and the levels of peptidoglycans were calculated as per the standard curve and expressed as $\mathrm{ng} / \mathrm{mL}$. The levels of lipopolysaccharides (LPS) were also measured by ELISA kit (\#EKC34448, Biomatik, Wilmington, DE) following the manufacturer's instruction manual. The levels of LPS were calculated by standard curve and expressed as $\mathrm{pg} / \mathrm{mL}$.

\section{Statistical analysis:}

Data were evaluated for presence of outliers and adherence to a normal distribution using GraphPad Prism, version 8.1 software. Statistical significance of normally and nonnormally distributed data were assessed via student's $t$-test and Mann-Whitney test, respectively, at $\mathrm{p}=0.05$. 


\section{Results:}

\section{Clinical characteristics of the COVID-19 patients and healthy individuals:}

We enrolled 30 patients confirmed to have COVID-19 infection (Table 1). At the time of admission to the hospital, all COVID-19 patients were experiencing nausea, myalgia, fever, diarrhea, and shortness of breath. The median age of all 30 patients was 63.3 years (range of 46-89 years) including 17 males and 13 females. Majority of the patients (17 patients) were considered to have moderate infection, while 11 patients experienced mild infection. Only 2 patients were reported as having severe COVID-19 on admission. Based on the severity of the symptoms and duration of the recovery period, the length of the hospital stay varied from 1-123 days. Thirty-four percent of patients (10 out of 30 ) were diabetic and $50 \%$ of patients (15 out of 30 ) in our cohort experienced thrombotic events. The body mass index (BMI) of 23 patients was greater than 25 . Five out of 30 patients died during their hospital stay. The blood samples from healthy individuals were collected during routine health visits and individuals were free from any complications (Table 2).

\section{Laboratory findings and COVID-19 manifestation in patients:}

Admission laboratories for the COVID-19 cohort included complete blood count (CBC) with differential and a metabolic panel. These results are detailed in Tables $\mathbf{3}$ and $\mathbf{4}$, respectively. $\mathrm{CBC}$ results indicated decreased abundance of lymphocytes and red blood cells (RBCs) in $47.8 \%$ and $64 \%$ of COVID-19 subjects, respectively. All COVID-19 subjects ( $n=23)$ exhibited abundance of monocytes above the normal range. Neutrophils, the first-responders of bacterial infection, were at an abundance above the normal range in $58.3 \%$ of male and $45.5 \%$ of female COVID-19 subjects. Total white blood cells counts were outside the normal range in $38.5 \%$ and $41.7 \%$ of COVID-19 subjects, respectively. Lastly, $16.7 \%$ of COVID-19 subjects exhibited platelets outside the normal range. 
Biochemical evaluation of these patients was performed as seen in Table 4. Of COVID19 positive subjects, $100 \%$ of those with BNP out of range $(n=3)$ were male of which one subject exhibited BNP between 100-200 pg/mL, likely indicative of compensated congestive heart failure (CHF), and two subjects with BNP $>400 \mathrm{pg} / \mathrm{mL}$, indicating likely moderate to severe CHF. All subjects exhibited CRP levels greater than normal of which four male subjects (44\%) and two female subjects (33\%) exhibited CRP $>100 \mathrm{mg} / \mathrm{L}$ which is associated with severe inflammation such as sepsis. Six male (75\%) and six female (100\%) subjects exhibited D-dimer levels higher than the normal range, indicating activation of the procoagulant and fibrinolytic systems. Five male (71.4\%) and three female (60\%) exhibited ferritin levels greater than the normal range of which two male (40\%) and two female subjects $(67 \%)$ had ferritin levels $>1000$ $\mathrm{ng} / \mathrm{mL}$ which can be associated acute or chronic inflammation. Twelve male (80\%) and 11 female (91.7\%) exhibited fasting glucose levels greater than the normal range. Nine male $(64.3 \%)$ and 8 female (66.7\%) subjects exhibited hemoglobin levels below the normal range. Six male $(85.7 \%)$ and six female (100\%) subjects exhibited LDH levels greater than normal. Of male subjects, four subjects (80\%) exhibited troponin-I levels above the normal range and one subject $(20 \%)$ had levels below the normal range. Of female subjects, one (16.7\%) exhibited troponin-I levels greater than the normal range. Troponin-I levels greater than the normal range suggest myocardial injury. Three male (60\%) and three female $(60 \%)$ subjects exhibited procalcitonin levels greater than the normal range with one male (33.3\%) and one female (33.3\%) subject exhibiting levels between $0.15-2.0 \mathrm{ng} / \mathrm{mL}$ and one male (33.3\%) subject with a procalcitonin level greater than $2 \mathrm{ng} / \mathrm{mL}$. Procalcitonin levels $<0.15 \mathrm{ng} / \mathrm{mL}$ indicate an unlikelihood of significant bacterial infection; whereas, levels between $0.15-2.0 \mathrm{ng} / \mathrm{mL}$ do not exclude the possibility of an infection, and levels $>2.0 \mathrm{ng} / \mathrm{mL}$ are highly suggestive of a significant bacterial infection. Reference values for laboratory measurements are provided in

\section{table 5.}




\section{Presence of gut microbial abundance in the blood of COVID-19 patients:}

Plasma samples were obtained under sterile conditions and evaluated for the presence of bacteria. Specifically, the taxonomic units, distribution of abundances, and alpha diversity were measured. Alpha diversity, a representation of the total microbial population in the sample, was assessed using Pielou's Evenness, Faith's Phylogenic Diversity, Observed Features Metrics, and Shannon's Index, (Fig.1A-D). A total of 152,536 sequencing reads were obtained from 14 COVID-19 plasma samples. 16S rRNA sequencing data suggests that $65 \%$ (9 out of 14 patient samples) yielded a strong bacterial signal. Alpha diversity revealed that the plasma microbiome for each patient exhibited unique evenness and richness. However, notable differences were observed in the Pielou's, Faith's, Observed, and Shannon index between samples. Beta diversity was determined using principal coordinate analysis (PCoA) (Fig.1E). Overall, the plasma microbiome community was not different between the COVID-19 samples.

\section{Phylogenic differences in plasma microbiome in the COVID-19 plasma samples:}

The dysbiosis index is a PCR-based assay and was performed to quantify the abundance of bacterial groups in the given samples. As shown in Fig.2A, a dysbiosis index was determined in the plasma of all the COVID-19 samples. The relative abundance of microbial composition in the COVID-19 samples is shown in Fig.2B. Three major phyla (Proteobacteria, Firmicutes, and Actinobacteria) were identified in all 9 samples. Patient 6, however, exhibited abundance of unidentified bacteria greater than all other subjects. At the phylum level, the enrichment of Proteobacteria was highest in all samples ranging from $22 \%-91 \%$, followed by Firmicutes (10\%-71\%), and Actinobacteria (6\%-27\%). Bacteroidetes was present in a very low percentage. Firmicutes abundance in $\mathrm{P} 7$ and $\mathrm{P} 12$, two of those which died during hospitalization, was low, suggesting plasma abundance of Firmicutes may be a prognostic marker of COVID-19 severity. 
Taxonomic abundance in the COVID-19 plasma samples:

Next, the abundance of each microbial population was assessed and revealed that, at the genus level (Fig.3), the prevalence of gram-negative bacteria (Acinetobacter, Nitrospirillum, Cupriavidus, Pseudomonas, Aquabacterium, Burkholderia, Caballeronia, Parabhurkholderia, Bravibacterium, and Sphingomonas) was higher than gram-positive bacteria (Staphylococcus and Lactobacillus) in COVID-19 plasma samples. Notably, LPS, a major cell wall component of gram-negative bacteria which contributes to the activation of inflammatory signaling pathways, was significantly increased in COVID-19 subject plasma $(p=0.0049)$, supporting the observed increase of gram-negative bacteria.

\section{SARS-CoV-2 infections promote gut barrier defects in COVID-19 patients:}

The plasma microbiome arises largely as a consequence of bacterial translocation from the gut into the systemic circulation ${ }^{31-36}$. Compromised intestinal barriers are an important pathogenic factor and contribute to promotion of inflammation. We measured gut permeability markers in the plasma of COVID-19 and control subjects. FABP2 is an intracellular protein which is expressed specifically in intestinal epithelial cells ${ }^{37}$ and binds free fatty acids, cholesterol, and retinoids, and is involved in intracellular lipid transport. During mucosal damage, mature epithelial cells release this protein into the circulation ${ }^{38}$ and higher levels of FABP2 in the plasma are associated with gut barrier defects 30373940 . To determine the integrity of the gut barrier in COVID-19 patients, the levels of FABP2 were measured. As seen in Fig.4A, the levels of FABP2 were higher in the plasma of COVID-19 patients $(1282 \pm 199.6 \mathrm{vs}$ 838.1 $\pm 91.33 ; p=0.0757$ ) compared with healthy individuals.

\section{The increased levels of gut microbial peptides (GMPs) into systemic circulation:}

GMPs initiate deleterious signaling pathways and contribute to systemic inflammation ${ }^{31}$ 41-50. To determine if gut barrier dysfunction led to translocation of GMPs into the system 
circulation of COVID-19 patients, we measured PGN and LPS in their plasma. Levels of PGN were nearly 2.5 times higher $(34.64 \pm 3.18$ vs $17.53 \pm 2.12 ; \mathrm{p}<0.0001)$ in COVID-19 patients compared with controls (Fig.4B). LPS, the major component of gram-negative bacterial cell walls, was found in higher levels $(405.5 \pm 48.37$ vs $249.6 \pm 17.06 ; p=0.0049)$ in COVID-19 samples compared with non-COVID-19 patients (Fig.4C).

\section{Discussion:}

Due to their role in regulating immune function and metabolism, gut microbes are key contributors in the maintenance of host health ${ }^{51-54}$. The fecal microbiota and its translocation from the gastrointestinal tract into systemic circulation has been considered as a key driver of immune response and systemic inflammation ${ }^{55-58}$. Abnormal presence of gut microbes in the plasma can initiate and intensify inflammatory cascades ${ }^{59}$. Although systemic and local tissue inflammation is paramount in the pathogenesis of COVID-19 infection, the clinical relevance of gut microbes in the plasma remains unclear. Therefore, in this study we sought to test the hypothesis that bacterial translocation from the intestine into the systemic circulation occurs and is associated with worsened outcomes in SARS-CoV-2 infection. Increased intestinal permeability due to mucosal barrier dysfunction could result in microbial translocation. Our results support that the COVID-19 patients exhibit gut barrier dysfunction as evidenced higher levels of FABP2, PGN, and LPS (Fig.4) and the presence of microbes in their plasma (Fig.1-3).

The duration of fecal viral shedding ranged from 1 to 33 days after symptomatic recovery of lung pathology 6061 . In children infected with SARS-CoV-2, rectal swabs were found positive for SARS-CoV-2 even after the nasopharynx was negative, suggesting that viral shedding from the digestive tract might be longer duration than that from the respiratory tract ${ }^{62}$.

During hospitalization, the fecal microbiome can be altered, thus, we selected to test the initial plasma samples of COVID-19 patients. In a small group of 9 patients, depletion of the commensal bacterium Lactobacillus was documented in 65\% patients during COVID-19 
infection. Commensal bacteria act on the host's immune system to induce a protective response and also inhibit the growth of respiratory pathogens ${ }^{63}$. Heeney et. al. reported reduced abundance of Lactobacillus in diabetes, obesity, and cancer ${ }^{64}$. Our data in Table 1 suggests that majority of COVID-19 patients were diabetic and obese as depicted from higher BMI. The microbial abundance of Acinetobacter, Nitrospirillum, Cupriavidus, Pseudomonas, Aquabacterium, Burkholderia, Caballeronia, Parabhurkholderia, Bravibacterium, and Sphingomonas) were higher in COVID-19 patients. Sepsis is defined as a life-threatening condition in which body's immune system damages its own tissues in response to infections ${ }^{65}$. The increased abundance of Gram-positive bacteria Staphylococcus in the bloodstream can cause sepsis and infective endocarditis ${ }^{66}$. Alhazzani et reported that most of the COVID-19 related deaths are caused by sepsis ${ }^{67}$. Even after viral clearing, there was a loss of salutary species in the majority of COVID-19 patients, suggesting that exposure to SARS-CoV-2 might be associated with more long-lasting deleterious effects on the gut microbiome.

While most studies to date examine the blood metabolome, rather than the blood microbiome, we first sought to establish whether the plasma microbiome existed in COVID-19 subjects and then determine if the microbial diversity supported that the origin of these microbes was the intestine ${ }^{6869}$. Results from numerous studies have linked the plasma metabolome to the gut microbiome and their implication for specific diseases ${ }^{70}$. Wikoff et. al. demonstrated that the gut microbiome dramatically influenced the composition of blood metabolites using MS-based methods and plasma extracts from germ-free mice compared with samples from conventional animals ${ }^{71}$. Bacterial-mediated production of bioactive indole-containing metabolites derived from tryptophan such as indoxyl sulfate and the antioxidant indole-3-propionic acid (IPA) have been identified in the plasma.

The fecal microbiome has been compared to the plasma metabolome in disease states such as ulcerative colitis where products of sphingolipid metabolism, specifically sphingosine 1phosphate in the blood correlate with Roseburia, Klebsiella, and Escherichia-Shigella ${ }^{72}$. 
Kurilshikov et. al. showed that the gut microbiome explained $11 \%$ to $16 \%$ of the variation in 231 major plasma metabolites ${ }^{73}$, highlighting its powerful impact on the host and the multidimensional interplay between gut bacteria and their ability to predict human disease or health.

Studies on the plasma microbiome are limited; however, Whittle et. al. performed a comprehensive evaluation of the blood microbiome in healthy and asthmatic individuals and found, at the phylum level, the blood microbiome was predominately composed of Proteobacteria, Actinobacteria, Firmicutes, and Bacteroidetes ${ }^{74}$. These key phyla detected were consistent irrespective of molecular method used for their identification (DNA vs. RNA), and were consistent with the results of other published studies ${ }^{75-78}$.

Studies by Serena et. al. demonstrate that celiac disease patients exhibit alterations in blood microbiome composition and taxonomic diversity compared to healthy subjects and they suggested that changes in the blood microbiome may contribute to the pathogenesis of celiac disease $^{79}$. Buford et al compared microbiota profiles of serum from healthy young (20-35 years) and older adults (60-75 years). They demonstrated that the richness and composition of the serum microbiome differ between these age groups and are linked to indices of age-related inflammation such as IL-6 and TNFa ${ }^{80}$.

Our studies provide evidence for the loss of gut barrier function in COVID-19 subjects, however, the mechanisms responsible have not been elucidated. A role for loss of intestinal angiotensin converting enzyme 2 and a dysregulated renin-angiotensin system is plausible. SARS-CoV-2, upon entry into the host, binds to the extracellular domain of ACE2 in the nose, lung, and gut epithelial cells through its spike glycoprotein subunit S1. In a healthy gut, ACE2 serves to chaperone amino acid transporters to the gut epithelial surface. At the gut epithelial surface, ACE2 dimerizes with $\mathrm{B}^{0} \mathrm{AT} 1$ and then a dimer of $\mathrm{ACE} 2$ : $\mathrm{B}^{0} \mathrm{AT} 1$ heterodimers activates mucosal enteroendocrine $L$ cells to release incretins, such as GLP-1 and GIP. Incretins enter the circulation to modulate glucose homeostasis. This key regulatory pathway can be disturbed 
in patients with COVID-19, even nondiabetics, and might explain, in part, new onset hyperglycemia that is seen in COVID-19 patients as well as deterioration of glucose control in diabetic subjects with COVID-19 infections. Amino acid absorption in the gut, regulated by the ACE2: $\mathrm{B}^{0} \mathrm{AT} 1$ modulates not only tryptophan absorption but also glutamine, and tryptophan serves to activate mTOR to release antimicrobial peptides that signal to down-regulate lymphoid proinflammatory cytokines and promote tight junction formation ${ }^{81} 82$. These natural defense mechanisms are disturbed by COVID-19 infection and can lead to a leaky gut.

This study has limitations including the absence of plasma microbiome samples in control subjects and the rather small size for COVID-19 subjects. Despite the limitations, we show conclusively that gut barrier leakage occurs in COVID-19 subjects. Taken together, we summarized our observations and show the presence of pathogenic bacteria in the plasma of COVID-19 subjects (Fig. 5). SARS-CoV-2 infection disrupts the gut barrier and leads to elevation of systemic bacterial lipopolysaccharide and peptidoglycan and serves to enhance systemic inflammation. Therefore, leaky gut and microbial dysbiosis could contribute to cytokine storm in patients severely ill with COVID -19.

\section{Authors Contributions:}

RP, MJP, and MBG conceived of the study and participated in the design. RP, MJP, SF, CPV, and MD were involved in sample collection. CSJ, JW, RL performed microbiome analysis. RP performed ELISA for gut permeability markers. RP and JLF performed data analyses and all figures, including Figure 5 with BioRender. RP, JLF, AH, and MBG wrote the manuscript. BRS provides expert guidance and critiques. All authors read and approved the final manuscript.

Sources of Funding: This study was supported by the National Institutes of Health Grants R01EY025383, R01EY012601, R01EY028858, and R01EY028037 to M.B.G. 
Disclosures: None

\section{Figure legends}

Figure 1: 16S rRNA analyses in the plasma of COVID-19 patients. Alpha diversity was measured by observed species richness within the samples (A-D). 2D principal coordinates analysis (PCoA) plots of weighted UniFrac distance reveal no difference among the patients(E).

Figure 2. Pathogen dysbiosis index (A) and dominant phyla (B) were observed in COVID-19 plasma. Pie charts representing the main phyla that constitute the blood microbiome in COVID19 samples.

Figure 3: A heatmap analysis of CPM normalized counts of Metaphlan displayed differential abundances of several prominent taxa in the COVID-19 plasma samples.

Figure 4. The SARS-CoV-2 infection causes gut barrier dysfunctions measured by higher levels of FABP2 (A), PGN (B), and LPS (C) in the plasma of COVID-19 patients. Data are presented as mean \pm S.E.M. Each dot represents a sample in the cohorts. ${ }^{*} p<0.07,{ }^{* *} p<0.0001$, ${ }^{* * *} p<0.0049$

Figure 5. Schematic diagram representing hypothesis of COVID-19 infection promotes gut barrier defects and translocation of gut microbiome into the systemic circulation resulting worse outcomes. 


\section{References:}

1. COVID-19 Weekly Cases and Deaths per 100,000 Population by Age, Race/Ethnicity, and Sex COVID Data Tracker: Centers for Disease Control and Prevention; 2021 [Available from: https://covid.cdc.gov/covid-data-tracker/\#demographicsovertime accessed 04/05/2021 2021.

2. Sanyaolu A, Okorie C, Marinkovic A, et al. Comorbidity and its Impact on Patients with COVID-19. SN Compr Clin Med 2020:1-8. doi: 10.1007/s42399-020-00363-4

3. Guzik TJ, Mohiddin SA, Dimarco A, et al. COVID-19 and the cardiovascular system: implications for risk assessment, diagnosis, and treatment options. Cardiovasc Res 2020;116(10):1666-87. doi: $10.1093 / c v r / c v a a 106$

4. Ruan Q, Yang K, Wang W, et al. Clinical predictors of mortality due to COVID-19 based on an analysis of data of 150 patients from Wuhan, China. Intensive Care Med 2020;46(5):846-48. doi: 10.1007/s00134-020-05991-x

5. Zhou F, Yu T, Du R, et al. Clinical course and risk factors for mortality of adult inpatients with COVID-19 in Wuhan, China: a retrospective cohort study. Lancet 2020;395(10229):1054-62. doi: 10.1016/S0140-6736(20)30566-3 [published Online First: 2020/03/15]

6. Dorjee K, Kim H, Bonomo E, et al. Prevalence and predictors of death and severe disease in patients hospitalized due to COVID-19: A comprehensive systematic review and meta-analysis of 77 studies and 38,000 patients. PLoS One 2020;15(12):e0243191. doi:

10.1371/journal.pone.0243191

7. Mehra MR, Desai SS, Kuy S, et al. Cardiovascular Disease, Drug Therapy, and Mortality in Covid-19. N Engl J Med 2020;382(25):e102. doi: 10.1056/NEJMoa2007621

8. Lim S, Bae JH, Kwon HS, et al. COVID-19 and diabetes mellitus: from pathophysiology to clinical management. Nat Rev Endocrinol 2021;17(1):11-30. doi: 10.1038/s41574-020-00435-4 
9. Lee LY, Cazier JB, Angelis V, et al. COVID-19 mortality in patients with cancer on chemotherapy or other anticancer treatments: a prospective cohort study. Lancet 2020;395(10241):1919-26. doi: 10.1016/S0140-6736(20)31173-9

10. Hunt RH, East JE, Lanas A, et al. COVID-19 and Gastrointestinal Disease: Implications for the Gastroenterologist. Dig Dis 2021;39(2):119-39. doi: 10.1159/000512152

11. El Moheb M, Naar L, Christensen MA, et al. Gastrointestinal Complications in Critically III Patients With and Without COVID-19. JAMA 2020 doi: 10.1001/jama.2020.19400 [published Online First: 2020/09/25]

12. Zhong P, Xu J, Yang D, et al. COVID-19-associated gastrointestinal and liver injury: clinical features and potential mechanisms. Signal Transduct Target Ther 2020;5(1):256. doi: 10.1038/s41392020-00373-7 [published Online First: 2020/11/04]

13. Giron LB, Dweep H, Yin X, et al. Severe COVID-19 Is Fueled by Disrupted Gut Barrier Integrity. medRxiv 2020:2020.11.13.20231209. doi: 10.1101/2020.11.13.20231209

14. Pan L, Mu M, Yang P, et al. Clinical Characteristics of COVID-19 Patients With Digestive Symptoms in Hubei, China: A Descriptive, Cross-Sectional, Multicenter Study. Am J Gastroenterol 2020;115(5):766-73. doi: 10.14309/ajg.0000000000000620 [published Online First: 2020/04/15]

15. Cheung KS, Hung IFN, Chan PPY, et al. Gastrointestinal Manifestations of SARS-CoV-2 Infection and Virus Load in Fecal Samples From a Hong Kong Cohort: Systematic Review and Meta-analysis. Gastroenterology 2020;159(1):81-95. doi: 10.1053/j.gastro.2020.03.065 [published Online First: 2020/04/07]

16. Sultan S, Altayar O, Siddique SM, et al. AGA Institute Rapid Review of the Gastrointestinal and Liver Manifestations of COVID-19, Meta-Analysis of International Data, and Recommendations for the Consultative Management of Patients with COVID-19. Gastroenterology 2020;159(1):320-34 e27. doi: 10.1053/j.gastro.2020.05.001 [published Online First: 2020/05/15] 
17. El Ouali S, Achkar JP, Lashner B, et al. Gastrointestinal manifestations of COVID-19. Cleve Clin J Med 2021 doi: 10.3949/ccjm.87a.ccc049 [published Online First: 2020/06/20]

18. Tuck MK, Chan DW, Chia D, et al. Standard operating procedures for serum and plasma collection: early detection research network consensus statement standard operating procedure integration working group. J Proteome Res 2009;8(1):113-7. doi: 10.1021/pr800545q

19. Li L, Tan C, Zeng J, et al. Analysis of viral load in different specimen types and serum antibody levels of COVID-19 patients. J Transl Med 2021;19(1):30. doi: 10.1186/s12967-020-02693-2

20. Walters W, Hyde ER, Berg-Lyons D, et al. Improved Bacterial 16S rRNA Gene (V4 and V4-5) and Fungal Internal Transcribed Spacer Marker Gene Primers for Microbial Community Surveys. mSystems 2016;1(1) doi: 10.1128/mSystems.00009-15 [published Online First: 2016/11/09]

21. Bolyen E, Rideout JR, Dillon MR, et al. Reproducible, interactive, scalable and extensible microbiome data science using QIIME 2. Nat Biotechnol 2019;37(8):852-57. doi: 10.1038/s41587-019-0209-9 [published Online First: 2019/07/26]

22. Rognes T, Flouri T, Nichols B, et al. VSEARCH: a versatile open source tool for metagenomics. PeerJ 2016;4:e2584. doi: 10.7717/peerj.2584 [published Online First: 2016/10/27]

23. Callahan BJ, McMurdie PJ, Rosen MJ, et al. DADA2: High-resolution sample inference from Illumina amplicon data. Nat Methods 2016;13(7):581-3. doi: 10.1038/nmeth.3869 [published Online First: $2016 / 05 / 24]$

24. Faith DP, Baker AM. Phylogenetic diversity (PD) and biodiversity conservation: some bioinformatics challenges. Evol Bioinform Online 2007;2:121-8. [published Online First: 2006/01/01]

25. DeSantis TZ, Hugenholtz P, Larsen N, et al. Greengenes, a chimera-checked $16 \mathrm{~S}$ rRNA gene database and workbench compatible with ARB. Appl Environ Microbiol 2006;72(7):5069-72. doi: 10.1128/AEM.03006-05 [published Online First: 2006/07/06] 
26. Pielou EC. The measurement of diversity in different types of biological collections. Journal of Theoretical Biology 1966;13:131-44. doi: 10.1016/0022-5193(66)90013-0

27. Shannon CE, and Weaver Warren. A Mathematical Theory of Communication. The Bell System Technical Journal 1948;27 (3):379-423. doi: doi.org/10.1002/j.1538-7305.1948.tb01338.x.

28. Paulson JN, Stine OC, Bravo HC, et al. Differential abundance analysis for microbial marker-gene surveys. Nat Methods 2013;10(12):1200-2. doi: 10.1038/nmeth.2658 [published Online First: 2013/10/01]

29. Lozupone CA, Hamady M, Kelley ST, et al. Quantitative and qualitative beta diversity measures lead to different insights into factors that structure microbial communities. Appl Environ Microbiol 2007;73(5):1576-85. doi: 10.1128/AEM.01996-06 [published Online First: 2007/01/16]

30. Stevens BR, Goel R, Seungbum K, et al. Increased human intestinal barrier permeability plasma biomarkers zonulin and FABP2 correlated with plasma LPS and altered gut microbiome in anxiety or depression. Gut 2018;67(8):1555-57. doi: 10.1136/gutjnl-2017-314759 [published Online First: 2017/08/18]

31. Belkaid Y, Hand TW. Role of the microbiota in immunity and inflammation. Cell 2014;157(1):121-41. doi: 10.1016/j.cell.2014.03.011 [published Online First: 2014/04/01]

32. Yan AW, Schnabl B. Bacterial translocation and changes in the intestinal microbiome associated with alcoholic liver disease. World J Hepatol 2012;4(4):110-8. doi: 10.4254/wjh.v4.i4.110

33. Keshavarzian A, Choudhary S, Holmes EW, et al. Preventing gut leakiness by oats supplementation ameliorates alcohol-induced liver damage in rats. J Pharmacol Exp Ther 2001;299(2):442-8.

34. Chakaroun RM, Massier L, Kovacs P. Gut Microbiome, Intestinal Permeability, and Tissue Bacteria in Metabolic Disease: Perpetrators or Bystanders? Nutrients 2020;12(4) doi: 10.3390/nu12041082 
35. Guarner C, Gonzalez-Navajas JM, Sanchez E, et al. The detection of bacterial DNA in blood of rats with CCl4-induced cirrhosis with ascites represents episodes of bacterial translocation. Hepatology 2006;44(3):633-9. doi: 10.1002/hep.21286

36. Runyon BA, Squier S, Borzio M. Translocation of gut bacteria in rats with cirrhosis to mesenteric lymph nodes partially explains the pathogenesis of spontaneous bacterial peritonitis. J Hepatol 1994;21(5):792-6. doi: 10.1016/s0168-8278(94)80241-6

37. Lau E, Marques C, Pestana D, et al. The role of I-FABP as a biomarker of intestinal barrier dysfunction driven by gut microbiota changes in obesity. Nutr Metab (Lond) 2016;13:31. doi: 10.1186/s12986-016-0089-7 [published Online First: 2016/05/03]

38. Pelsers MM, Namiot Z, Kisielewski W, et al. Intestinal-type and liver-type fatty acid-binding protein in the intestine. Tissue distribution and clinical utility. Clin Biochem 2003;36(7):529-35. doi: 10.1016/s0009-9120(03)00096-1 [published Online First: 2003/10/18]

39. Graupera I, Coll M, Pose E, et al. Adipocyte Fatty-Acid Binding Protein is Overexpressed in Cirrhosis and Correlates with Clinical Outcomes. Sci Rep 2017;7(1):1829. doi: 10.1038/s41598-017-017090 [published Online First: 2017/05/14]

40. Zhang J, Zhao D, Yi D, et al. Microarray analysis reveals the inhibition of intestinal expression of nutrient transporters in piglets infected with porcine epidemic diarrhea virus. Sci Rep 2019;9(1):19798. doi: 10.1038/s41598-019-56391-1 [published Online First: 2019/12/26]

41. Wang J, Chen WD, Wang YD. The Relationship Between Gut Microbiota and Inflammatory Diseases: The Role of Macrophages. Front Microbiol 2020;11:1065. doi: 10.3389/fmicb.2020.01065

42. Sochocka M, Donskow-Lysoniewska K, Diniz BS, et al. The Gut Microbiome Alterations and Inflammation-Driven Pathogenesis of Alzheimer's Disease-a Critical Review. Mol Neurobiol 2019;56(3):1841-51. doi: 10.1007/s12035-018-1188-4 
43. Ichinohe T, Pang IK, Kumamoto $\mathrm{Y}$, et al. Microbiota regulates immune defense against respiratory tract influenza A virus infection. Proc Natl Acad Sci U S A 2011;108(13):5354-9. doi: 10.1073/pnas.1019378108

44. Fernandez-Tome S, Marin AC, Ortega Moreno L, et al. Immunomodulatory Effect of Gut MicrobiotaDerived Bioactive Peptides on Human Immune System from Healthy Controls and Patients with Inflammatory Bowel Disease. Nutrients 2019;11(11) doi: 10.3390/nu11112605

45. Yucel G, Zhao Z, El-Battrawy I, et al. Lipopolysaccharides induced inflammatory responses and electrophysiological dysfunctions in human-induced pluripotent stem cell derived cardiomyocytes. Sci Rep 2017;7(1):2935. doi: 10.1038/s41598-017-03147-4

46. Zhao J, Bi W, Xiao S, et al. Neuroinflammation induced by lipopolysaccharide causes cognitive impairment in mice. Sci Rep 2019;9(1):5790. doi: 10.1038/s41598-019-42286-8

47. Fang $\mathrm{H}$, Pengal RA, Cao X, et al. Lipopolysaccharide-induced macrophage inflammatory response is regulated by SHIP. J Immunol 2004;173(1):360-6. doi: 10.4049/jimmunol.173.1.360

48. Wolf AJ, Underhill DM. Peptidoglycan recognition by the innate immune system. Nat Rev Immunol 2018;18(4):243-54. doi: 10.1038/nri.2017.136

49. Hoijer MA, Melief MJ, Debets R, et al. Inflammatory properties of peptidoglycan are decreased after degradation by human N-acetylmuramyl-L-alanine amidase. Eur Cytokine Netw 1997;8(4):37581.

50. Laman JD, t Hart BA, Power C, et al. Bacterial Peptidoglycan as a Driver of Chronic Brain Inflammation. Trends Mol Med 2020;26(7):670-82. doi: 10.1016/j.molmed.2019.11.006

51. Rothschild D, Weissbrod O, Barkan E, et al. Environment dominates over host genetics in shaping human gut microbiota. Nature 2018;555(7695):210-15. doi: 10.1038/nature25973

52. Zhang H, Sparks JB, Karyala SV, et al. Host adaptive immunity alters gut microbiota. ISME J 2015;9(3):770-81. doi: 10.1038/ismej.2014.165 
53. Hakansson A, Molin G. Gut microbiota and inflammation. Nutrients 2011;3(6):637-82. doi:

\section{$10.3390 /$ nu3060637}

54. Willis E. Nurses and independent fee-for-service practice: a critical view. Contemp Nurse 1993;2(3):135-42. doi: 10.5172/conu.2.3.135

55. Xu W, Luo Z, Alekseyenko AV, et al. Distinct systemic microbiome and microbial translocation are associated with plasma level of anti-CD4 autoantibody in HIV infection. Sci Rep 2018;8(1):12863. doi: 10.1038/s41598-018-31116-y

56. Luo Z, Li M, Wu Y, et al. Systemic translocation of Staphylococcus drives autoantibody production in HIV disease. Microbiome 2019;7(1):25. doi: 10.1186/s40168-019-0646-1

57. Dinh DM, Volpe GE, Duffalo C, et al. Intestinal microbiota, microbial translocation, and systemic inflammation in chronic HIV infection. J Infect Dis 2015;211(1):19-27. doi: 10.1093/infdis/jiu409

58. Villanueva-Millan MJ, Perez-Matute $P$, Recio-Fernandez E, et al. Differential effects of antiretrovirals on microbial translocation and gut microbiota composition of HIV-infected patients. J Int AIDS Soc 2017;20(1):21526. doi: 10.7448/IAS.20.1.21526

59. Dhar D, Mohanty A. Gut microbiota and Covid-19- possible link and implications. Virus Res 2020;285:198018. doi: 10.1016/j.virusres.2020.198018

60. Jones DL, Baluja MQ, Graham DW, et al. Shedding of SARS-CoV-2 in feces and urine and its potential role in person-to-person transmission and the environment-based spread of COVID-19. Sci Total Environ 2020;749:141364. doi: 10.1016/j.scitotenv.2020.141364 [published Online First: 2020/08/25]

61. Gupta S, Parker J, Smits S, et al. Persistent viral shedding of SARS-CoV-2 in faeces - a rapid review. Colorectal Dis 2020;22(6):611-20. doi: 10.1111/codi.15138 [published Online First: 2020/05/18] 
62. Xu Y, Li X, Zhu B, et al. Characteristics of pediatric SARS-CoV-2 infection and potential evidence for persistent fecal viral shedding. Nat Med 2020;26(4):502-05. doi: 10.1038/s41591-020-0817-4 [published Online First: 2020/04/15]

63. Khan R, Petersen FC, Shekhar S. Commensal Bacteria: An Emerging Player in Defense Against Respiratory Pathogens. Front Immunol 2019;10:1203. doi: 10.3389/fimmu.2019.01203

64. Heeney DD, Gareau MG, Marco ML. Intestinal Lactobacillus in health and disease, a driver or just along for the ride? Curr Opin Biotechnol 2018;49:140-47. doi: 10.1016/j.copbio.2017.08.004

65. Singer M, Deutschman CS, Seymour CW, et al. The Third International Consensus Definitions for Sepsis and Septic Shock (Sepsis-3). JAMA 2016;315(8):801-10. doi: 10.1001/jama.2016.0287

66. David MZ, Daum RS. Community-associated methicillin-resistant Staphylococcus aureus: epidemiology and clinical consequences of an emerging epidemic. Clin Microbiol Rev 2010;23(3):616-87. doi: 10.1128/CMR.00081-09

67. Alhazzani W, Moller MH, Arabi YM, et al. Surviving Sepsis Campaign: guidelines on the management of critically ill adults with Coronavirus Disease 2019 (COVID-19). Intensive Care Med 2020;46(5):854-87. doi: 10.1007/s00134-020-06022-5

68. Wang J, Gu X, Yang J, et al. Gut Microbiota Dysbiosis and Increased Plasma LPS and TMAO Levels in Patients With Preeclampsia. Front Cell Infect Microbiol 2019;9:409. doi: 10.3389/fcimb.2019.00409

69. Vojinovic D, Radjabzadeh D, Kurilshikov A, et al. Relationship between gut microbiota and circulating metabolites in population-based cohorts. Nat Commun 2019;10(1):5813. doi: 10.1038/s41467019-13721-1

70. Wilmanski T, Rappaport N, Earls JC, et al. Blood metabolome predicts gut microbiome alpha-diversity in humans. Nat Biotechnol 2019;37(10):1217-28. doi: 10.1038/s41587-019-0233-9 [published Online First: 2019/09/04] 
71. Wikoff WR, Anfora AT, Liu J, et al. Metabolomics analysis reveals large effects of gut microflora on mammalian blood metabolites. Proc Natl Acad Sci U S A 2009;106(10):3698-703. doi: 10.1073/pnas.0812874106 [published Online First: 2009/02/24]

72. Sun M, Du B, Shi Y, et al. Combined Signature of the Fecal Microbiome and Plasma Metabolome in Patients with Ulcerative Colitis. Med Sci Monit 2019;25:3303-15. doi: 10.12659/MSM.916009 [published Online First: 2019/05/06]

73. Kurilshikov A, van den Munckhof ICL, Chen L, et al. Gut Microbial Associations to Plasma Metabolites Linked to Cardiovascular Phenotypes and Risk. Circ Res 2019;124(12):1808-20. doi: 10.1161/CIRCRESAHA.118.314642 [published Online First: 2019/04/12]

74. Whittle E, Leonard MO, Harrison R, et al. Multi-Method Characterization of the Human Circulating Microbiome. Front Microbiol 2018;9:3266. doi: 10.3389/fmicb.2018.03266 [published Online First: 2019/02/02]

75. Amar J, Lange C, Payros G, et al. Blood microbiota dysbiosis is associated with the onset of cardiovascular events in a large general population: the D.E.S.I.R. study. PLoS One 2013;8(1):e54461. doi: 10.1371/journal.pone.0054461 [published Online First: 2013/02/02]

76. Lelouvier B, Servant F, Paisse S, et al. Changes in blood microbiota profiles associated with liver fibrosis in obese patients: A pilot analysis. Hepatology 2016;64(6):2015-27. doi: 10.1002/hep.28829 [published Online First: 2016/09/18]

77. Paisse S, Valle C, Servant F, et al. Comprehensive description of blood microbiome from healthy donors assessed by 16 S targeted metagenomic sequencing. Transfusion 2016;56(5):1138-47. doi: 10.1111/trf.13477 [published Online First: 2016/02/13]

78. Olde Loohuis LM, Mangul S, Ori APS, et al. Transcriptome analysis in whole blood reveals increased microbial diversity in schizophrenia. Trans/ Psychiatry 2018;8(1):96. doi: 10.1038/s41398-0180107-9 [published Online First: 2018/05/11] 
79. Gloria Serena CD, Murat Cetinbas, Ruslan I. Sadreyev, Alessio Fasano. Analysis of blood and fecal microbiome profile in patients with celiac disease. Human Microbiome Journal 2019;11,100049 doi: doi.org/10.1016/j.humic.2018.12.001.

80. Buford TW, Carter CS, VanDerPol WJ, et al. Composition and richness of the serum microbiome differ by age and link to systemic inflammation. Geroscience 2018;40(3):257-68. doi: 10.1007/s11357018-0026-y [published Online First: 2018/06/06]

81. Perlot T, Penninger JM. ACE2 - from the renin-angiotensin system to gut microbiota and malnutrition. Microbes Infect 2013;15(13):866-73. doi: 10.1016/j.micinf.2013.08.003 [published Online First: 2013/08/22]

82. Obukhov AG, Stevens BR, Prasad R, et al. SARS-CoV-2 Infections and ACE2: Clinical Outcomes Linked With Increased Morbidity and Mortality in Individuals With Diabetes. Diabetes 2020;69(9):187586. doi: 10.2337/dbi20-0019 [published Online First: 2020/07/17] 
A
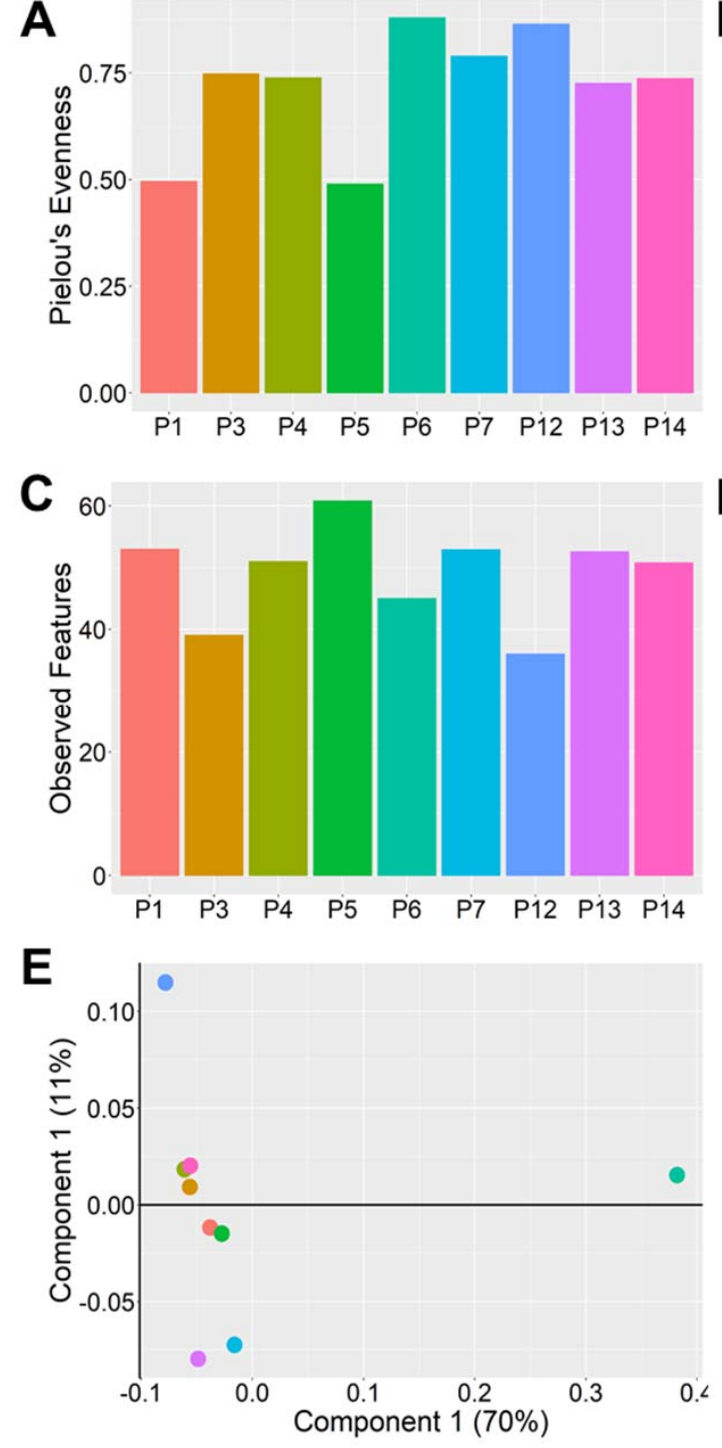
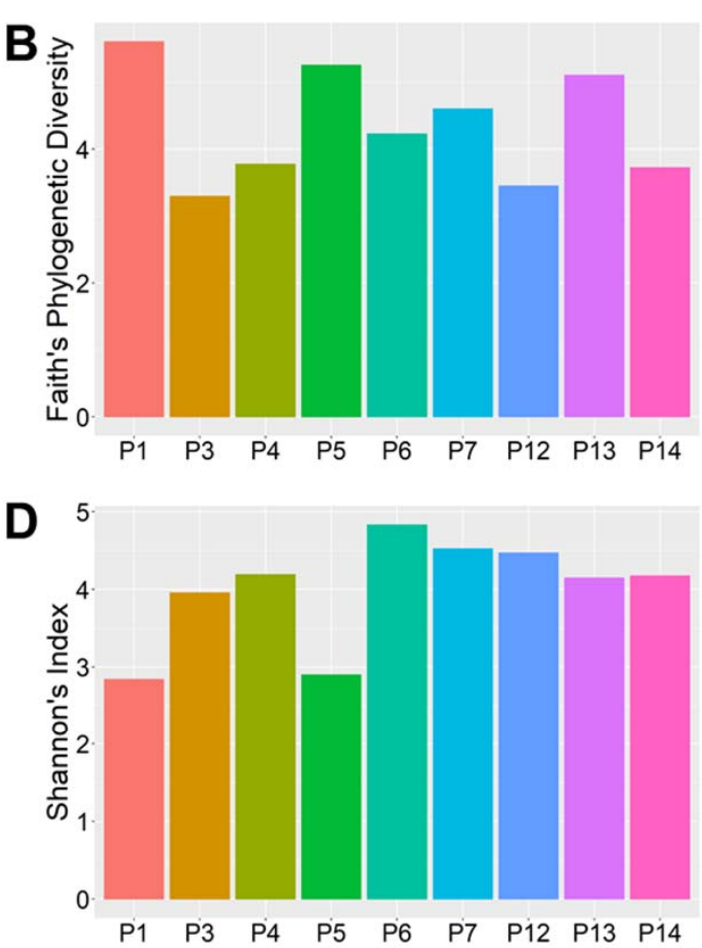

Figure 1: Prasad et al 


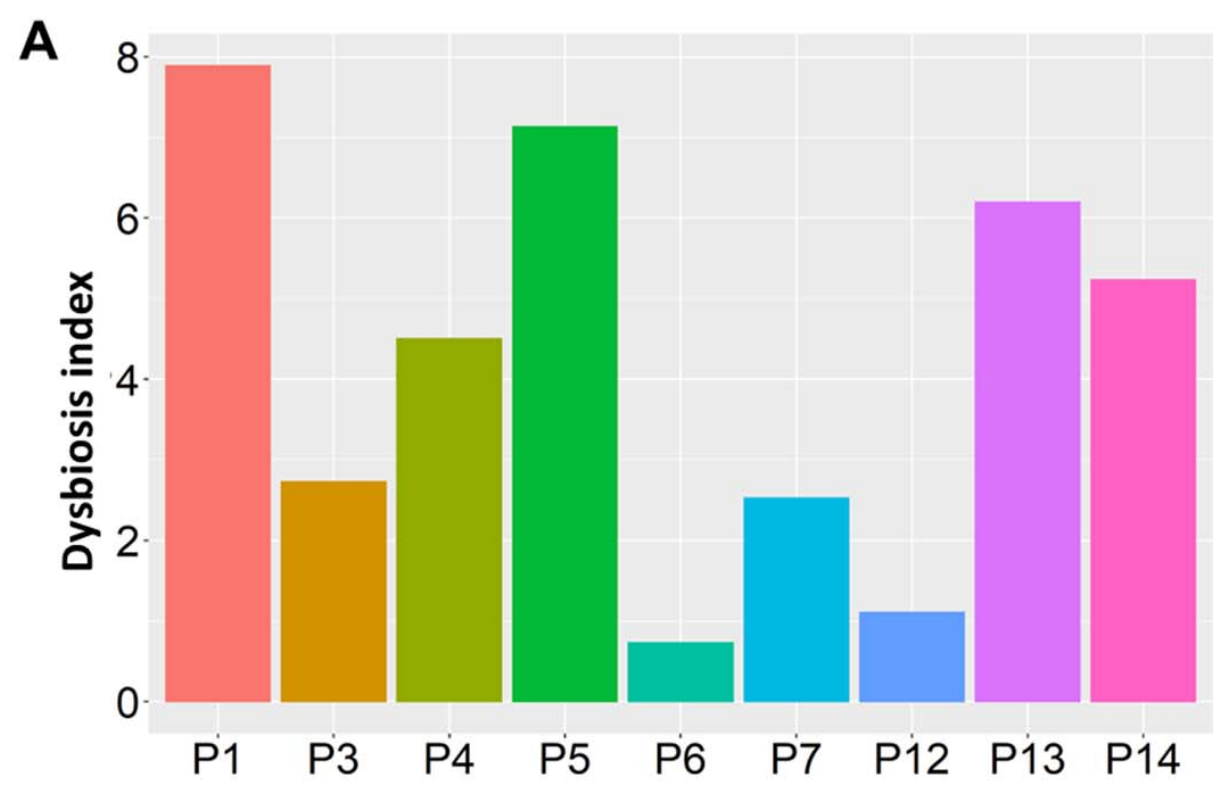

B

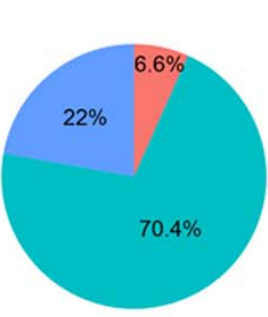

P1

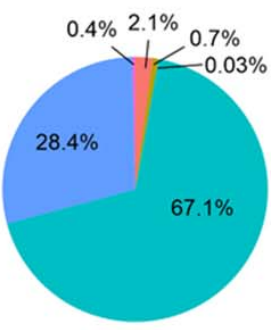

P5

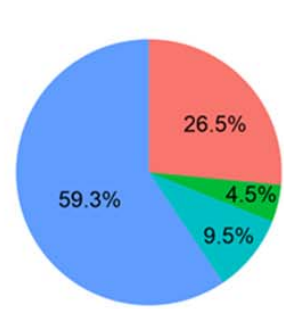

P12

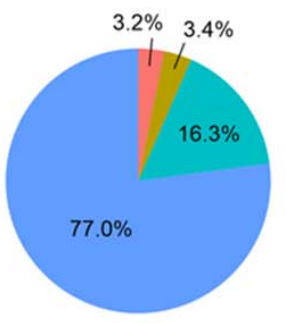

P3

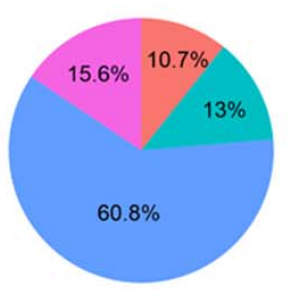

P6

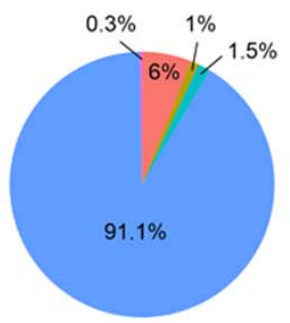

P13

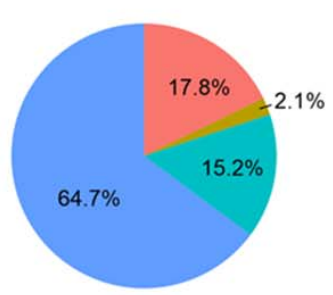

P4

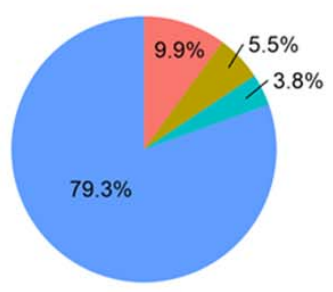

P7

Phylum
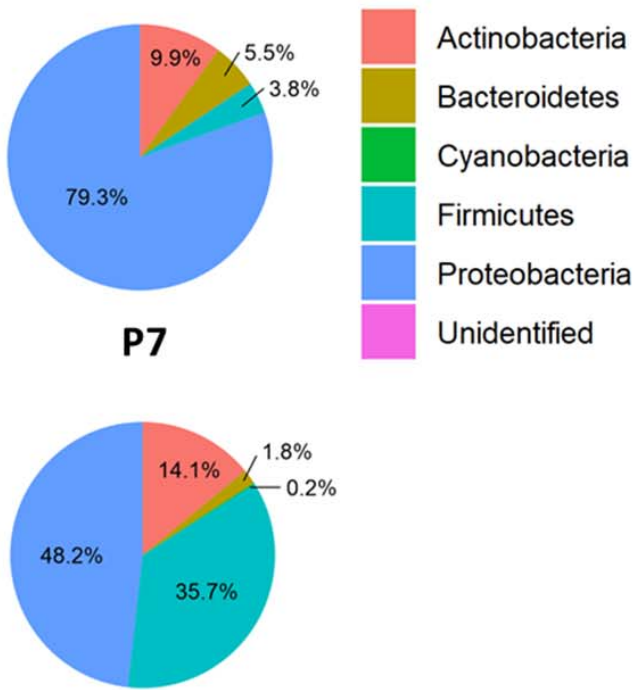

P14

Figure 2: Prasad et al 
bioRxiv preprint doi: https://doi.org/10.1101/2021.04.06.438634; this version posted April 6, 2021. The copyright holder for this preprint (which was not certified by peer review) is the author/funder. All rights reserved. No reuse allowed without permission.

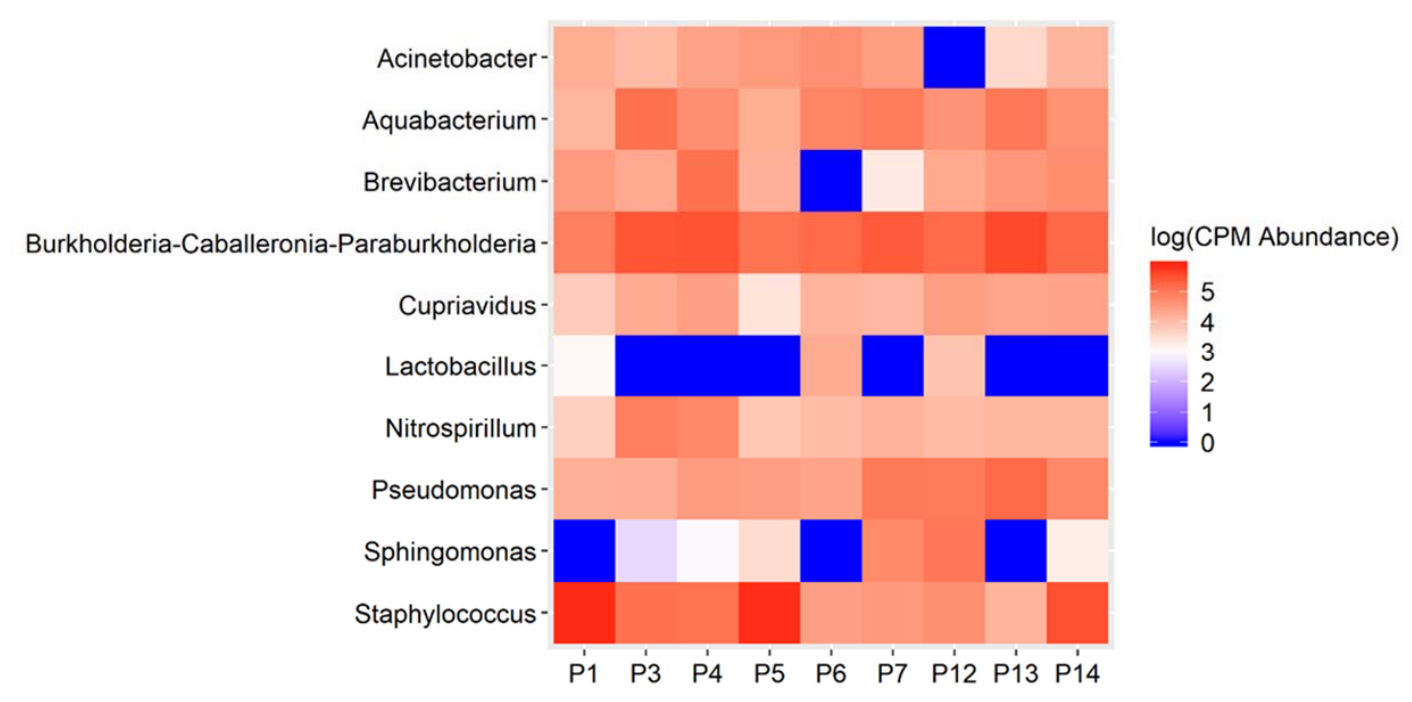

Figure 3: Prasad et al 

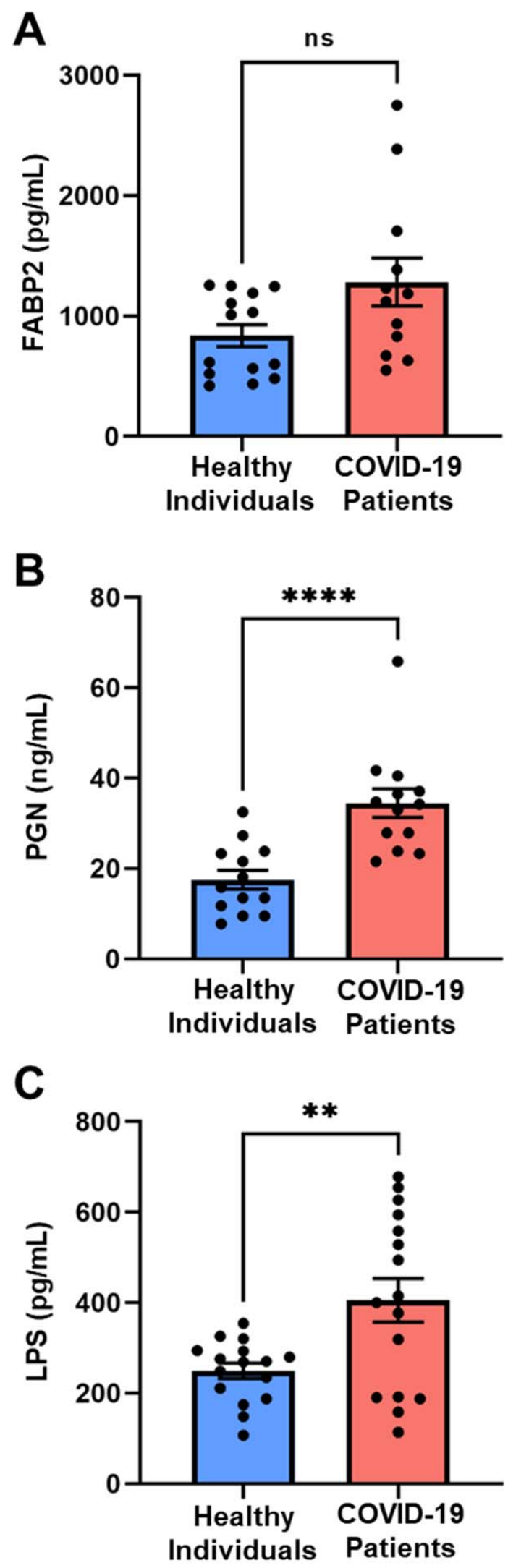

Figure 4: Prasad et al 


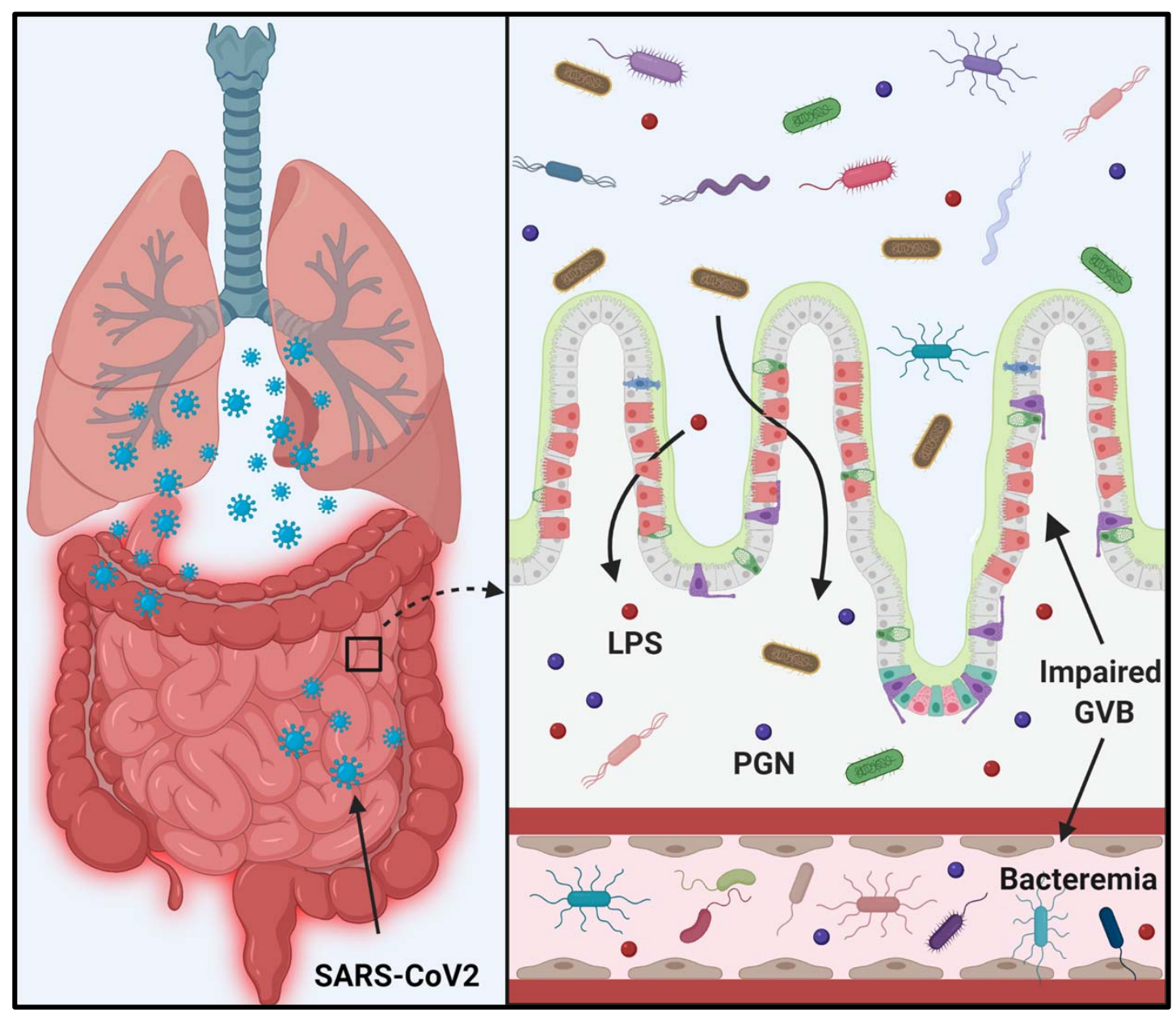

Figure 5: Prasad et al 
Table 1: Basic characteristics of COVID-19 patients.

\begin{tabular}{|c|c|c|c|c|c|c|c|c|c|}
\hline $\begin{array}{l}\text { Patient's } \\
\text { Code }\end{array}$ & $\begin{array}{l}\text { Patient's } \\
\text { Case ID }\end{array}$ & Sex & $\begin{array}{l}\text { Age } \\
\text { (Years) }\end{array}$ & BMI & $\begin{array}{l}\text { COVID-19 } \\
\text { infection }\end{array}$ & $\begin{array}{l}\text { In Hospital } \\
\text { (Days) }\end{array}$ & Diabetes & $\begin{array}{l}\text { Thrombotic } \\
\text { Events }\end{array}$ & $\begin{array}{l}\text { Current } \\
\text { Status }\end{array}$ \\
\hline P1 & 747 & Male & 63 & 36.94 & Mild & 49 & Yes & Yes & - \\
\hline P2 & 784 & Male & 49 & - & Moderate & 123 & Yes & Yes & - \\
\hline P3 & 756 & Male & 81 & - & Moderate & 30 & - & Yes & Deceased \\
\hline P4 & 729 & Male & 49 & 35.08 & Mild & 23 & Yes & - & - \\
\hline P5 & 765 & Female & 70 & 26.99 & Moderate & 8 & - & - & - \\
\hline P6 & 785 & Male & 76 & - & Moderate & 4 & - & - & - \\
\hline P7 & 678 & Female & 71 & 33.38 & Moderate & 16 & - & Yes & Deceased \\
\hline P8 & 708 & Female & 52 & 47.55 & Mild & 14 & Yes & - & - \\
\hline P9 & 724 & Female & 46 & 33.28 & Moderate & 25 & - & Yes & Deceased \\
\hline P10 & 700 & Male & 55 & 37.37 & Moderate & 11 & - & Yes & - \\
\hline P11 & 703 & Male & 56 & 27.12 & Mild & 2 & - & - & - \\
\hline P12 & 775 & Male & 69 & 30.41 & Moderate & 25 & - & Yes & Deceased \\
\hline P13 & 690 & Female & 69 & 41.88 & Moderate & 4 & Yes & - & - \\
\hline P14 & 685 & Male & 48 & 29.99 & Mild & 2 & - & - & - \\
\hline P15 & 695 & Male & 64 & 28.5 & Mild & 2 & Yes & Yes & - \\
\hline P16 & 739 & Female & 54 & 32.24 & Mild & 1 & - & - & - \\
\hline P17 & 704 & Female & 64 & 19.74 & Mild & 1 & - & - & - \\
\hline P18 & 761 & Female & 70 & - & Moderate & 22 & Yes & - & - \\
\hline P19 & 798 & Male & 55 & 29.38 & Severe & 11 & - & - & - \\
\hline P20 & 769 & Male & 51 & 28.75 & Moderate & 6 & - & Yes & - \\
\hline P21 & 766 & Male & 67 & 37.66 & Moderate & 1 & - & Yes & - \\
\hline P22 & 764 & Female & 62 & 46.52 & Severe & 28 & Yes & Yes & - \\
\hline P23 & 698 & Male & 83 & 26.63 & Moderate & 18 & - & Yes & Deceased \\
\hline P24 & 771 & Female & 63 & 30.62 & Moderate & 4 & Yes & - & - \\
\hline P25 & 791 & Male & 68 & 27.45 & Moderate & 22 & Yes & - & - \\
\hline P26 & 706 & Male & 89 & 26.11 & Mild & 25 & - & Yes & - \\
\hline P27 & 720 & Female & 73 & - & Moderate & 5 & - & - & - \\
\hline P28 & 722 & Male & 71 & 32.61 & Mild & 5 & - & - & - \\
\hline P29 & 694 & Female & 59 & 21.14 & Moderate & 21 & - & Yes & - \\
\hline P30 & 693 & Female & 52 & - & Mild & 1 & - & Yes & - \\
\hline
\end{tabular}

Due to low bacterial yield, sample codes P2, and P8-P11 were not included in microbiome analysis. 
Table 2: Basic characteristics of healthy subjects. Plasma samples from these healthy controls were used in gut permeability analysis.

\begin{tabular}{lllll}
\hline $\begin{array}{l}\text { Healthy control's } \\
\text { code }\end{array}$ & Sex & Age & Comorbidity & Current Status \\
\hline H1 & Female & 35 & None & Living \\
H2 & Female & 60 & None & Living \\
H3 & Male & 56 & None & Living \\
H4 & Male & 26 & None & Living \\
H5 & Female & 43 & None & Living \\
H6 & Female & 28 & None & Living \\
H7 & Male & 42 & None & Living \\
H8 & Female & 34 & None & Living \\
H9 & Female & 34 & None & Living \\
H10 & Female & 22 & None & Living \\
H11 & Female & 72 & None & Living \\
H12 & Male & 45 & None & Living \\
H13 & Male & 55 & None & Living \\
H14 & Female & 32 & None & Living \\
H15 & Female & 33 & None & Living \\
H16 & Male & 32 & None & Living \\
\hline
\end{tabular}


Table 3: Analytical observation of immunological cell population in the plasma samples of COVID-19 patients.

\begin{tabular}{|c|c|c|c|c|c|c|c|c|}
\hline $\begin{array}{l}\text { Patient's } \\
\text { Code }\end{array}$ & $\begin{array}{l}\text { Basophils } \\
(\%)\end{array}$ & $\begin{array}{l}\text { Eosinophils } \\
(\%)\end{array}$ & $\begin{array}{l}\text { Lymphocytes } \\
(\%)\end{array}$ & $\begin{array}{l}\text { Monocytes } \\
(\%)\end{array}$ & $\begin{array}{l}\text { Neutrophils } \\
(\%)\end{array}$ & $\begin{array}{l}\text { Platelets } \\
\left(10^{\wedge} 3 / \mathrm{cmm}\right)\end{array}$ & $\begin{array}{l}\text { RBC } \\
\left(10^{\wedge} 6 / \mathrm{cmm}\right)\end{array}$ & $\begin{array}{l}\text { WBC } \\
\left(10^{\wedge} 3 / \mathrm{cmm}\right)\end{array}$ \\
\hline $\mathrm{P} 1$ & 0.44 & 1.33 & 17.62 & 10.26 & 70.36 & 233.44 & 2.93 & 8.18 \\
\hline $\mathrm{P} 2$ & 1.02 & 1.85 & 30.34 & 6.65 & 59.05 & 498.69 & 3.99 & 9.89 \\
\hline P3 & - & - & - & - & - & - & - & - \\
\hline P4 & 0.68 & 1.8 & 14.52 & 7.36 & 75.23 & 335.08 & 3.17 & 8.94 \\
\hline P5 & 0.4 & 0.13 & 8.2 & 6.7 & 86 & 307.47 & 4.87 & 9.03 \\
\hline P6 & - & - & - & - & - & - & - & - \\
\hline P7 & 0.27 & 0.1 & 1.81 & 1.59 & 96.37 & 166.37 & 3.00 & 6.79 \\
\hline P8 & 0.18 & 0.07 & 85.13 & 2.27 & 13.36 & 164.13 & 4.06 & 39.76 \\
\hline P9 & 0.84 & 2.09 & 22.52 & 6.15 & 68.64 & 295.4 & 3.4 & 8.78 \\
\hline P10 & 0.75 & 2.6 & 13.24 & 5.7 & 78.11 & 191.06 & 4.36 & 11.06 \\
\hline P11 & - & - & - & - & - & - & - & - \\
\hline P12 & 0.3 & 0.1 & 11.1 & 3.0 & 86 & 211.7 & 4.6 & 5.51 \\
\hline P13 & 0.2 & - & 36.8 & 6.6 & 56 & 151.9 & 5.09 & 3.59 \\
\hline P14 & 0.57 & 2.76 & 18.16 & 7.15 & 71.78 & 276.2 & 2.84 & 9.63 \\
\hline P15 & 1.27 & 2.5 & 27 & 13.33 & 56.03 & 142.4 & 2.74 & 3.84 \\
\hline P16 & 0.6 & 0.6 & 26.8 & 6.3 & 66 & 423.8 & 4.91 & 16.86 \\
\hline P17 & 0.5 & 2.1 & 43.7 & 13.4 & 40 & 82.7 & 2.88 & 6.26 \\
\hline P18 & 0.4 & 0.3 & 15.3 & 9.8 & 74 & 185.5 & 3.91 & 8.16 \\
\hline P19 & 0.2 & 0.4 & 5.4 & 6.1 & 88 & 341.4 & 4.1 & 9.71 \\
\hline P20 & 0.2 & 0.2 & 22.2 & 7.5 & 70 & - & 5.33 & 7.09 \\
\hline P21 & - & - & - & - & - & 268.8 & 4.39 & 9.34 \\
\hline P22 & 0.4 & 0.1 & 10.9 & 9.0 & 82 & 231.7 & 4.96 & 6.99 \\
\hline P23 & - & 1.1 & 3.2 & 3.9 & 93 & 290.1 & 4.2 & 27.66 \\
\hline P24 & - & - & - & - & - & 263.2 & 5.32 & 4.52 \\
\hline P25 & 0.8 & 0.3 & 4 & 12.7 & 82 & 308.6 & 4.11 & 14.62 \\
\hline P26 & - & - & - & - & - & - & - & - \\
\hline P27 & 0.4 & 0.4 & 30.3 & 21.2 & 48 & 328.9 & 3.49 & 2.10 \\
\hline P28 & - & - & 4 & 4 & 92 & 241.2 & 4.72 & 15.54 \\
\hline P29 & 0.9 & 1.1 & 15.6 & 5.4 & 77 & 161.1 & 2.9 & 13.68 \\
\hline P30 & - & - & - & - & - & - & - & - \\
\hline
\end{tabular}

RBC: Red blood cells; WBC: White blood cells. 
Table 4: Biochemical observations in the plasma samples of COVID-19 patients.

\begin{tabular}{|c|c|c|c|c|c|c|c|c|c|c|}
\hline $\begin{array}{l}\text { Patient's } \\
\text { Code }\end{array}$ & $\begin{array}{l}\text { BNP } \\
\text { (pg/mL) }\end{array}$ & $\begin{array}{l}\mathbf{C R P} \\
(\mathrm{mg} / \mathrm{L})\end{array}$ & $\begin{array}{l}\text { D-Dimer } \\
\text { (ng/mL) }\end{array}$ & $\begin{array}{l}\text { Ferritin } \\
(\mathrm{ng} / \mathrm{mL})\end{array}$ & $\begin{array}{l}\text { Glucose } \\
\text { (mg/dL) }\end{array}$ & $\begin{array}{l}\mathbf{H g b} \\
\text { (gm/dL) }\end{array}$ & $\begin{array}{l}\text { Lactic acid } \\
(\mathrm{mm} / \mathrm{L})\end{array}$ & $\begin{array}{l}\text { LDH } \\
\text { (units/l) }\end{array}$ & $\begin{array}{l}\text { Hs Troponin-I } \\
(\mathrm{ng} / \mathrm{L})\end{array}$ & $\begin{array}{l}\text { Procalcitonin } \\
\text { (ng/mL) }\end{array}$ \\
\hline $\mathrm{P} 1$ & 515 & 56.27 & 1914.51 & 503.67 & 160.11 & 8.56 & 1.34 & 291 & 182.92 & 0.7 \\
\hline $\mathrm{P} 2$ & 77 & 64.89 & 439.62 & 351 & 212.81 & 11.28 & 1.24 & 320.33 & - & - \\
\hline P3 & - & - & - & - & - & - & - & - & - & - \\
\hline $\mathrm{P} 4$ & - & 208.61 & - & 187 & 202.74 & 8.69 & 1.8 & - & 6.5 & - \\
\hline P5 & 69 & - & - & - & 120.5 & 12.8 & - & - & 5.3 & - \\
\hline P6 & - & - & - & - & - & - & - & - & - & - \\
\hline P7 & - & 67.77 & 1298 & 1489 & 148.35 & 8.89 & 1.4 & 1636.9 & 28.17 & 0.08 \\
\hline P8 & 25 & 25.12 & 308.38 & 108 & 134.3 & 10.39 & 0.8 & 346.33 & 3.33 & 0.02 \\
\hline P9 & 53 & 138.16 & 188.69 & 4552 & 123.73 & 9.91 & 1.84 & 503 & 8.57 & 0.8 \\
\hline P10 & 136 & 431.79 & 1744.77 & 1462 & 114 & 13.93 & 2.76 & 2221 & 98.27 & 26.46 \\
\hline $\mathrm{P} 11$ & - & 115.98 & 176.82 & 292 & 195.5 & 12.9 & - & 221 & - & 0.07 \\
\hline P12 & 22 & 26.1 & 568.57 & 2105 & 175 & 15.4 & - & 331 & 24.3 & 0.09 \\
\hline $\mathrm{P} 13$ & 51 & 59.01 & 577.28 & 379 & 137.69 & 7.91 & 0.79 & 399 & 5.1 & 0.12 \\
\hline P14 & - & 25.92 & 218.04 & 477 & 104.39 & 15.96 & - & 273 & - & 0.07 \\
\hline P15 & - & - & - & - & 78 & 8 & - & - & - & - \\
\hline P16 & - & - & - & - & 118 & 14.3 & - & - & - & - \\
\hline P17 & - & - & - & - & 262 & 9.5 & - & - & - & - \\
\hline P18 & - & - & - & - & 111 & 10.2 & - & - & - & - \\
\hline P19 & - & - & - & - & 143 & 11.8 & - & - & 2.3 & - \\
\hline P20 & - & - & - & - & 220 & 14.0 & - & - & - & - \\
\hline P21 & - & - & - & - & 100 & 12.7 & - & - & - & - \\
\hline P22 & 88 & 130.22 & 410.68 & 63 & 167 & 13.1 & 1.8 & 272 & 4.0 & 0.07 \\
\hline P23 & 551 & 297.31 & 9842.0 & - & 207 & 12.3 & - & - & 2865.8 & - \\
\hline P24 & - & - & - & - & 420 & 12.9 & - & - & - & - \\
\hline P25 & - & - & - & - & 301 & 12.2 & - & - & - & - \\
\hline P26 & - & - & - & - & 99 & - & - & - & - & - \\
\hline P27 & - & 26.67 & 632.68 & - & 113 & 9.5 & - & 303 & - & - \\
\hline P28 & - & 20.76 & 414.04 & - & 113 & 14.5 & - & 280 & - & - \\
\hline P29 & - & - & - & - & 99 & 10.0 & - & - & - & - \\
\hline P30 & - & - & - & - & - & - & - & - & - & - \\
\hline
\end{tabular}

BNP: Brain natriuretic peptide; CRP:C-reactive protein; Hgb: Hemoglobin; LDH: Lactate dehydrogenase. 
Table 5. Reference values for CBC with differential and biochemical panel in healthy individuals.

\begin{tabular}{lcccc}
\hline \multirow{2}{*}{ Parameters } & \multicolumn{2}{c}{ Male } & \multicolumn{2}{c}{ Female } \\
\cline { 2 - 5 } & Low & High & Low & High \\
\hline Basophils (\%) & 0 & 2 & 0 & 2 \\
Eosinophils (\%) & 0 & 5 & 0 & 5 \\
Lymphocytes (\%) & 15 & 52.0 & 15 & 52 \\
Monocytes (\%) & 0.16 & 1.43 & 0.16 & 1.43 \\
Neutrophils (\%) & 35 & 73 & 35 & 73 \\
Platelets (10^3/cmm) & 150 & 400 & 150 & 400 \\
RBC (10^6/cmm) & 4.4 & 5.8 & 3.8 & 5.2 \\
WBC (10^3/cmm) & 4 & 11 & 4 & 11 \\
BNP (pg/mL) & 0 & 100 & 0 & 100 \\
CRP (mg/L) & 0 & 10.9 & 0 & 10.9 \\
D-Dimer (ng/mL) & 0 & 240 & 0 & 240 \\
Ferritin (ng/mL) & 23.9 & 336.2 & 11 & 306.8 \\
Glucose (mg/dL) & 70 & 100 & 70 & 100 \\
Hgb (gm/dL) & 13.5 & 17 & 11.3 & 15.2 \\
Lactic acid (mm/L) & 0.5 & 2.2 & 0.5 & 2.2 \\
LDH (units/l) & 120 & 240 & 120 & 240 \\
Hs Troponin-I (ng/L) & 3 & 20 & 3 & 15 \\
Procalcitonin (ng/mL) & 0 & 0.07 & 0 & 0.07 \\
\hline
\end{tabular}

